\title{
Systemic and mucosal humoral responses to Helicobacter pylori in gastric cancer
}

\author{
J E Crabtree, J I Wyatt, G M Sobala, G Miller, D S Tompkins, J N Primrose, A G Morgan
}

\begin{abstract}
The systemic IgG response to Helicobacter pylori was examined in 70 patients with gastric cancer. $H$ pylori IgG antibodies were assayed by enzyme linked immunosorbent assay (ELISA), and serological recognition of $H$ pylori antigens was characterised by western blotting. A percentage of 78.5 were seropositive by ELISA. Two of five patients under age 50 were seronegative. Positivity was unrelated to age, sex, tumour type, or site. Ninety one per cent of ELISA positive cancer patients recognised the $H$ pylori cytotoxin associated 120 kilodalton (KD) protein, significantly more than a control group of 47 ELISA positive patients with non-ulcer dyspepsia (72\%). Four of 15 ELISA negative cancer patients also showed recognition of this protein in western blots. Mucosal IgA responses to $H$ pylori were examined by immunoblotting supernatants of in vitro cultured resected antral mucosa in an overlapping group of 19 gastric cancer patients. Eighteen had a positive response, including 10 of 11 negative for $H$ pylori by biopsy urease testing. The systemic and local immunoblotting results show that the high seroprevalence of $\boldsymbol{H}$ pylori antibodies detected by ELISA is nevertheless an underestimate of past infection. Dyspepsia screening policies based solely on $\boldsymbol{H}$ pylori ELISA would miss some young patients with gastric cancer. Further study of the relation of the $H$ pylori cytotoxin to gastric precancerous lesions is warranted.
\end{abstract}

(Gut 1993; 34: 1339-1343)

Helicobacter pylori is a causative agent of chronic gastritis $^{1-3}$ and infection is strongly associated with peptic ulcer disease. ${ }^{1}$ There is a strong systemic $^{4-7}$ and mucosal ${ }^{89}$ antibody response to the bacterium. Patients whose gastritis has progressed to severe atrophy have a lower incidence of gastric $H$ pylori infection than non-atrophic subjects, ${ }^{10-12}$ but the former are often $H$ pylori seropositive, indicative of previous infection. ${ }^{10} 11$

Atrophic gastritis is a precursor condition for gastric carcinoma ${ }^{13}$ and therefore the question has been raised as to whether $H$ pylori is a causative factor in gastric carcinogenesis. Three longterm prospective studies have established a positive association between $H$ pylori seropositivity and subsequent development of gastric carcinoma. ${ }^{14-16}$ Additionally, in regions with a high incidence of gastric cancer, there is a high level of $H$ pylori seropositivity ${ }^{17}$ particularly in children. ${ }^{18}$ Histological studies, however, which have examined the relation between gastric cancer and $H$ pylori infection ${ }^{19-22}$ have found a great variability in the histological fre- quency of $H$ pylori, ranging from 19 to $80 \% .{ }^{23}$ This probably reflects problems associated with obtaining adequate non-tumour tissue and in detecting the organism in resection material. Additionally, extensive intestinal metaplasia ${ }^{11}$ or changed gastric microflora associated with hypochlorhydria may militate against continued infection with $H$ pylori. ${ }^{10} \mathrm{H}$ pylori serology in patients presenting with gastric cancer should give a more accurate indication of both current and past ${ }^{10}$ infection. There are currently, however, only limited serological data available from the United States $^{24}$ and Finland. ${ }^{21}$

The relations between $H$ pylori positivity and gastric cancer type - (that is, intestinal $v$ diffuse) and tumour site - (that is, cardia $v$ non-cardia) are still unclear. Furthermore, the possibility of using $H$ pylori serology to screen dyspeptic patients before endoscopy, ${ }^{25}$ makes it imperative that we know the prevalence of $H$ pylori seropositivity in patients with gastric cancer. The aims of this study were firstly to examine $H$ pylori seropositivity in a United Kingdom population with gastric cancer and its relation to age, tumour type, and site.

Secondly, as there is increasing evidence of strain heterogeneity in $H$ pylori ${ }^{2627}$ and recent studies from an area with a high incidence of gastric cancer have shown that cytotoxic strains of $H$ pylori ${ }^{26}$ are more frequently associated with atrophic gastritis, ${ }^{28}$ we characterised the specific $H$ pylori antigens recognised serologically by western blotting with particular respect to the cytotoxin associated 120 kilodalton (kD) protein. ${ }^{27}$

Finally, as severe atrophic gastritis can be associated with histological negativity for the organism but serological positivity, ${ }^{10}$ we examined the mucosal IgA antibody response to $H$ pylori in patients with gastric cancer and its relation with bacterial positivity and systemic IgG responses.

\section{Methods}

\section{GASTRIC CANCER PATIENTS}

Serum samples were obtained from 70 patients with gastric cancer (mean age 66.7, 43 men, 27 women) diagnosed between 1989 and 1991 . Samples were taken either at the time of endoscopy or before gastric surgery. Patients who had received recent blood transfusions and those who had had previous gastric surgery were excluded. Serum was stored at $-20^{\circ} \mathrm{C}$ until assayed.

The gastric carcinomas were classified histologically according to the Lauren system ${ }^{29}$ by one histopathologist without knowledge of the experimental results.

Freshly resected non-neoplastic antral mucosa

\author{
Correspondence to: \\ Dr J E Crabtree, Department \\ of Clinical Medicine, S \\ LS9 7TF \\ Accepted for publication \\ 23 February 1993 \\ Gastroenterology Unit, \\ Airedale General \\ A G Morgan
}


was obtained from an overlapping group of 19 patients (mean (SEM)) age 68.2 $(9 \cdot 8)$ with gastric adenocarcinoma (2 cardia, 17 non-cardia). Serum was available from seven of these subjects. Five biopsy specimens were taken for examination of urease activity using the CLO test (Delta West Ltd, Bentley, Australia). The remaining antral mucosa was cultured in vitro.

As resected gastric mucosa from patients without neoplasia was not available, antral endoscopic biopsy specimens obtained from 25 patients with histologically normal and $H$ pylori negative antral mucosa (mean age $46(16 \cdot 7)$ ) were used as controls for western blotting.

To determine the prevalence of serum IgG antibodies to the $120 \mathrm{kD}$ cytotoxin associated protein of $H$ pylori in ELISA positive patients without gastric cancer, 47 patients with nonulcer dyspepsia ( 24 men, 23 women, mean age $52.2(15.9))$ from the same regional area were examined.

\section{IN VITRO CULTURE}

Using aseptic techniques, freshly resected gastric mucosa was sectioned into biopsy sized pieces and cultured in vitro for three days in RPMI 1640 supplemented with $10 \%$ fetal calf serum (FCS) and $40 \mu \mathrm{g} / \mathrm{ml}$ gentamicin as previously described. ${ }^{30}$ The medium was changed daily and culture supernatants stored at $-70^{\circ} \mathrm{C}$ until western blotting was done. Endoscopic antral specimens were cultured using similar techniques.

\section{ELISA FOR H PYLORI}

Serum $H$ pylori IgG antibodies were assayed by ELISA as previously described. ${ }^{78}$ This assay uses an ultracentrifuged sonicated antigen preparation of $H$ pylori. The cut off for positivity was determined using serum from 116 patients of known histological $H$ pylori status. The sensitivity and specificity of the ELISA were $97 \%$ and $95 \%$ respectively.

\section{SDS-PAGE AND WESTERN BLOTTING}

Whole cell preparations of $H$ pylori (NCTC 11637), grown for 72 hours on Columbia agar (Oxoid, Basingstoke) with 5\% defibrinated horse blood, were prepared for sodium dodecyl sulfate polyacrylamide gel electrophoresis as previously described.$^{78}$ After electrophoresis (10\% separating gel, 5\% stacking gel), proteins were transferred to nitrocellulose paper (Schleicher and Schuell Co) by semi dry blotting ( 80 minutes at $145 \mathrm{~mA}$ in an LKB NovaBlotter). Serum samples were immunoblotted for $H$ pylori IgG antibodies at a dilution of 1 in 50 in a miniblotter apparatus (Biometra, Manchester) as previously described. ${ }^{7}$ Positive and negative control serum samples were included in each assay.

Gastric culture supernatants from cancer patients and controls were immunoblotted for $H$ pylori IgA antibodies. ${ }^{89}$ Immunoblots were considered positive if five or more bands were present. To confirm the specificity of the local IgA response to $H$ pylori, positive culture supernatants were preabsorbed for two hours at $26^{\circ} \mathrm{C}$ with whole cell preparations of $H$ pylori as previously described ${ }^{8}$ and immunoblotted together with unabsorbed supernatants. Culture supernatants were also immunoblotted against whole cell preparations of Campylobacter jejuni (NCTC 11168), C fetus subsp fetus (NCTC 10348) and $C$ sputorum subsp sputorum (NCTC 11528).

\section{STATISTICAL ANALYSIS}

The association of positivity with age was tested for by a $\chi^{2}$ test for linear trend. Differences in proportions between groups were tested by Yates's corrected $\chi^{2}$ or Fisher's exact test as appropriate.

\section{Results}

\section{H PYLORI SEROLOGY}

Fifty five of 70 gastric cancer patients $(78 \cdot 6 \%$, $95 \% \mathrm{Cl}: 67 \cdot 1$ to $87 \cdot 5 \%$ ) were seropositive for $H$ pylori IgG antibodies by ELISA. The percentage of seropositives was similar in men (79\%) and women $(78 \%)$.

Table I shows the relation between $H$ pylori seropositivity and age of presentation with gastric cancer. Three of five patients under 50 years were seropositive (aged 38, 41, and 47). The two $H$ pylori seronegative patients were 44 and 37 years. There was no significant trend for seropositivity with age $\left(\chi^{2}=0.047, \mathrm{p}>0.80\right)$ (Table I).

Eighteen of 70 patients had adenocarcinoma of the cardia, 47 had non-cardia cancer, and five gastric tumours were of unclassified origin because of extensive tumour infiltration. $H$ pylori seropositivity in patients with non-cardia cancer $(83 \%)$ was not significantly different from those with cancer of the cardia (72\%) (Fisher's exact test $2 p>0.04$ ).

Table II shows the relation between the histological type of cancer and $H$ pylori serology. There was a trend for increased seropositivity in intestinal type cancer compared with diffuse type but this did not reach significance (Yates's corrected $\chi^{2}=1.99, \mathrm{p}>0 \cdot 15$ ).

\section{WESTERN BLOTTING ANALYSIS OF SERUM IgG AND} GASTRIC IgA RESPONSES TO $H$ PYLORI

Figure I shows the serum IgG recognition of $H$ pylori whole cell preparations in western blots. In the gastric cancer patients antigen recognition patterns by the systemic IgG response were comparatively homogeneous particularly with respect to antigens between 60 to $120 \mathrm{kD}$. Fifty of 55 ELISA positive patients with gastric cancer $(91 \%, 95 \% \mathrm{Cl}: 80$ to $97 \%)$ showed serum IgG recognition of the cytotoxin associated $120 \mathrm{kD}$ protein. Interestingly, four of 15 ELISA negative cancer patients $(27 \%)$ also recognised this protein (Fig 1). The prevalence of recognition of the $120 \mathrm{kD}$ protein in the ELISA positive cancer patients $(91 \%)$ was significantly higher than in the ELISA positive controls with non-ulcer dyspepsia (72\%) (Yates's corrected $\chi^{2}=4 \cdot 80$, $\mathrm{p}=0.028$ ).

The biopsy urease test was positive at 24 hours histopathology

\begin{tabular}{lrrr}
\hline Histology & No & Positive & $\%$ \\
\hline Diffuse & 33 & 23 & 70 \\
Intestinal & 26 & 23 & 88 \\
Mixed & 6 & 5 & 83 \\
Unclassified & 5 & 4 & 80 \\
\hline
\end{tabular}




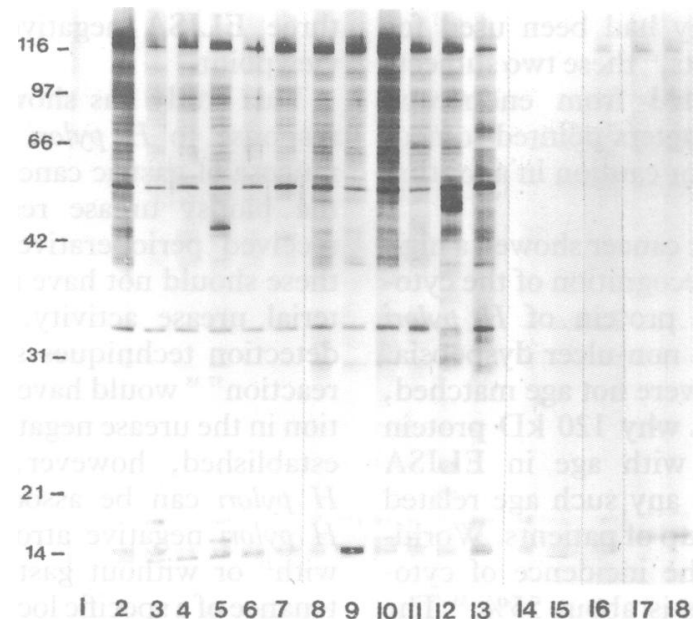

Figure 1: Western blot of serum IgG antibodies to $\mathrm{H}$ pylori in patients with gastric cancer. Track $I=$ negative second layer only control, tracks 2-13 H pylori ELISA positive patients, tracks 14-18 ELISA negative patients. Left hand figures refer to molecular weight standards in kilodaltons. Tracks 2-13 and 16-18 show recognition of the $120 \mathrm{kD}$ protein.

in eight of 19 patients (42\%) from whom fresh non-neoplastic resected gastric mucosa was obtained. Western blotting of the gastric culture supernatants showed a positive mucosal IgA response to $H$ pylori in 18 of 19 subjects (95\%) (Fig 2). Ten of 11 patients who were negative by the biopsy urease test nevertheless had a strong IgA response to the bacterium (Fig 2). The patient in track 1 was judged as negative, lacking strong recognition of five or more bands. By contrast with the systemic IgG responses, the mucosal IgA recognition of $H$ pylori showed considerable heterogeneity.

Preabsorption with $H$ pylori removed immunoreactivity in western blotting (Fig 3). Immunoblotting of gastric culture supernatants for IgA

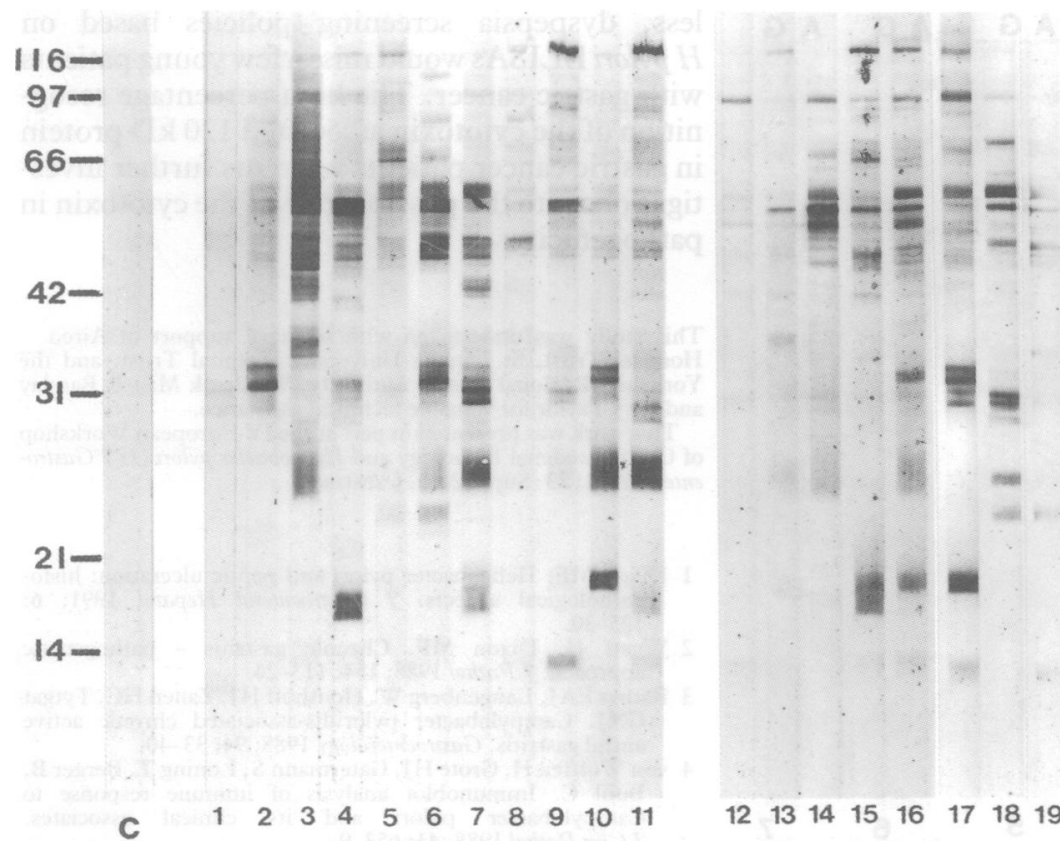

Figure 2: Western blot of IgA antibodies to $\mathrm{H}$ pylori in gastric culture supernatants of cancer patients. $C=\mathrm{H}$ pylori negative control with histologically normal antral mucosa. Tracks 1-11 urease negative patients, tracks 12-19 urease positive patients. Left hand figures refer to molecular weight standards in kilodaltons. antibodies against $C$ jejuni, $C$ fetus, and $C$ sputorum showed minimal cross reactivity. By contrast with the gastric cancer patients, only one of 25 culture supernatants of histologically normal endoscopic and $H$ pylori negative antral specimens showed a positive mucosal IgA reactivity to $H$ pylori by western blotting.

Comparative analysis of the local $\operatorname{IgA}$ and systemic IgG responses to $H$ pylori in patients with gastric cancer (Fig 4) showed some variability in antigen recognition patterns between mucosal and systemic sites. Local IgA positivity to $H$ pylori was evident in three ELISA IgG seronegative subjects. These three patients showed minimal IgG response by western blotting recognising less than five bands, but one (track 5) recognised the $120 \mathrm{kD}$ protein.

\section{Discussion}

The $78.5 \% H$ pylori seropositivity in patients with gastric cancer seen in this study confirms reports from the United States ${ }^{24}$ and Finland ${ }^{21}$ of a high prevalence of $H$ pylori infection in gastric cancer. In these latter studies, $H$ pylori seropositivity was $52 \%$ (both cardia and non-cardia) ${ }^{24}$ and $70 \%$ (non-cardia only). ${ }^{21}$ Although local data exist for the seroprevalence of $H$ pylori infection in dyspeptic patients ${ }^{31}$ and blood donors, ${ }^{32}$ neither of these are an adequate control group to contrast against the cancer patients and therefore such an analysis was not performed. An ideal control group would be age, sex, social class, and geographically matched, for example, patients drawn from general practitioner patient registers. This was not practicable within the constraints of this study.

We found no significant trend for seropositivity with age in gastric cancer patients in this study, confirming earlier findings of Sipponen et al. ${ }^{21}$

No significant difference in $H$ pylori seropositivity was found between patients presenting with cardia $v$ non-cardia cancer. This contrasts with the results of Talley et al, ${ }^{24}$ who found a significantly lower seropositivity in cancer of the cardia. ${ }^{24}$ Two longterm prospective studies from the United States also suggest a lack of association between $H$ pylori infection and cancer of the cardia. ${ }^{14}{ }^{16}$ Our findings with respect to cardia cancers may reflect high background prevalence of $H$ pylori seropositivity locally; the incidence of which in local dyspeptic patients over 70 years of age is as high as $70 \%$.

$H$ pylori seropositivity was similar in both intestinal and diffuse types of gastric cancer. Although one histological study suggested $H$ pylori prevalence in the intestinal type was greater than diffuse gastric cancer, ${ }^{20}$ both longterm prospective studies ${ }^{14}{ }^{16}$ and this and other recent serological studies ${ }^{2124}$ in patients presenting with gastric cancer show equal prevalences of $H$ pylori infection with both histological types of gastric cancer.

Two of the subjects under 45 years of age with gastric cancer were $H$ pylori seronegative. Both had diffuse type gastric cancer and their nonneoplastic gastric mucosa was histologically normal. About $25 \%$ of gastric cancers are considered not to be associated with $H$ pylori infec- 


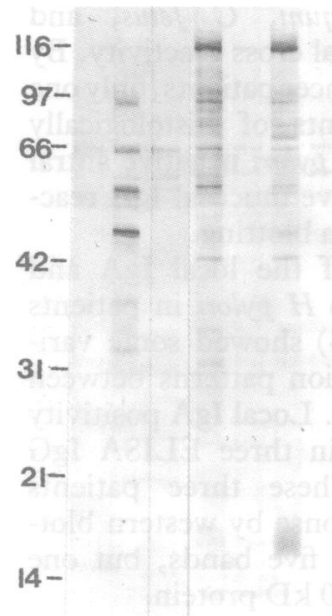

C 1223456

Figure 3: Western blot of IgA antibodies to $\mathrm{H}$ pylori in three gastric cancer culture supernatants before (tracks 1, 3, and 5) and after (tracks 2, 4, and 6) absorption with $\mathrm{H}$ pylori. $C=\mathrm{H}$ pylori negative control with histologically normal antral mucosa. Left hand figures refer to molecular weight standards in kilodaltons. tion. ${ }^{21}$ If $H$ pylori serology had been used for screening dyspeptic patients, ${ }^{25}$ these two subjects would have been excluded from endoscopy unless other clinical parameters pointed to neoplasia, suggesting a need for caution in adopting such screening methods.

The patients with gastric cancer showed a high percentage of serological recognition of the cytotoxin associated $120 \mathrm{kD}$ protein of $H$ pylori compared with those with non-ulcer dyspepsia. Although the two groups were not age matched, there is no $a$ priori reason why $120 \mathrm{kD}$ protein recognition should vary with age in ELISA positive subjects, nor was any such age related trend evident in either group of patients. Worldwide studies show that the incidence of cytotoxicity in $H$ pylori strains is about $55 \% .{ }^{33}$ The recent findings of Fox et $a l,{ }^{28}$ showing a high prevalence of cytotoxin positive strains in chronic atrophic gastritis in New Orleans, suggest that the cytotoxin may have a role in cancer precursor lesions as well as being associated with peptic ulceration. ${ }^{962734}$ Treatment studies have shown that patients whose antibody concentrations fall to below the threshold for ELISA seropositivity retain western blot positivity for the $120-130 \mathrm{kD}$ protein up to 24 months after eradication. ${ }^{35}$ The $120 \mathrm{kD}$ protein is not enriched in the antigen preparation used in the ELISA and addition of purified $120 \mathrm{kD}$ protein to standard ELISA antigen preparations improves serological detection of $H$ pylori infection in dyspeptic patients. ${ }^{36}$ Twenty seven per cent of the ELISA negative subjects with gastric cancer in this study recognised this protein by western blotting pointing to previous $H$ pylori infection. Thus the true prevalence of current and previous $H$ pylori infection in patients developing gastric cancer could be greater than that detected serologically by ELISA at the time of presentation. The presence of a gastric IgA response to $H$ pylori in

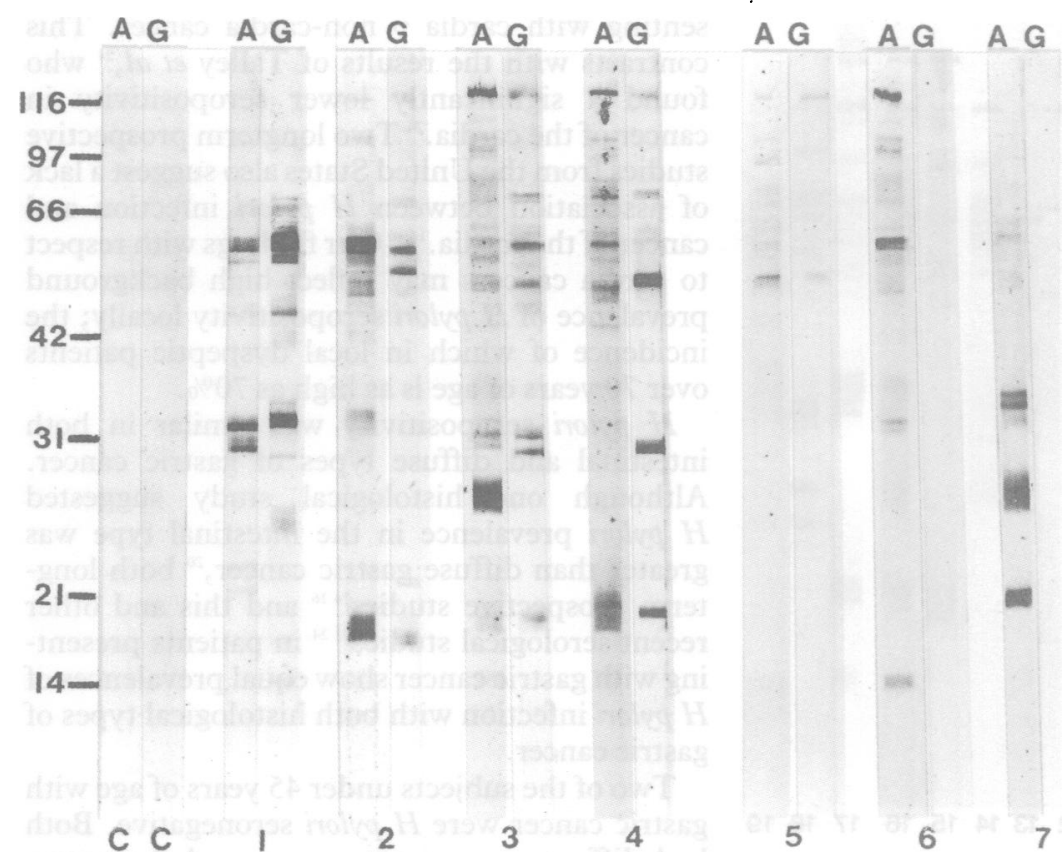

Figure 4: Western blot of gastric $\operatorname{IgA}(A)$ and serum $\operatorname{IgG}(G)$ antibodies to $\mathrm{H}$ pylori in patients with gastric cancer. $C=$ control with histologically normal antral mucosa. Tracks $1-4$ $\mathrm{H}$ pylori ELISA positive patients, tracks 5-7 ELISA negative patients. Left hand figures refer to molecular weight standards in kilodaltons. three ELISA negative patients supports this viewpoint.

This study has shown a strong mucosal IgA response to $H$ pylori in non-neoplastic antral mucosa of gastric cancer patients irrespective of the biopsy urease results. Although patients received perioperative intravenous antibiotics, these should not have immediately affected bacterial urease activity. Perhaps more sensitive detection techniques such as polymerase chain reaction ${ }^{37}{ }^{38}$ would have shown bacterial colonisation in the urease negative patients. It is now well established, however, that seropositivity for $H$ pylori can be associated with histologically $H$ pylori negative atrophic gastritis in patients with $^{21}$ or without gastric cancer. ${ }^{1011}$ The maintenance of a specific local immune response in the absence of $H$ pylori could result from a number of causes. Lipopolysaccharide from non-Helicobacter gram negative organisms, which colonise the gastric environment after the development of hypochlorhydria, could stimulate the local production of cytokines such as interleukin-6. Interleukin-6 is important in terminal maturation of $B$ cells ${ }^{39}$ and could non-specifically stimulate gastric mucosal B cells thus maintaining a local $H$ pylori specific IgA response after eradication of infection. Our recent studies have shown very high secretion of antral interleukin-6 in patients with extensive intestinal metaplasia ${ }^{40}$ and epithelial cells are becoming increasingly recognised as a potential source of proinflammatory cytokines. ${ }^{4142}$ Alternatively, the presence of cross reacting epitopes between $H$ pylori and the gastric mucosa ${ }^{434}$ could be responsible for the maintenance of bacterial specific responses after the loss of $H$ pylori infection with gastric atrophy.

In conclusion, this study shows a high prevalence of $H$ pylori seropositivity in patients in the United Kingdom with gastric cancer, which did not vary significantly with age, site, or type of tumour. Western blotting data suggest that the ELISA results are an underestimate. Nevertheless, dyspepsia screening policies based on $H$ pylori ELISAs would miss a few young patients with gastric cancer. The high percentage recognition of the cytotoxin associated $120 \mathrm{kD}$ protein in gastric cancer patients warrents further investigations into the possible role of the cytotoxin in pathogenicity.

This study was undertaken with financial support of Airedale Hospital Trust, St James's University Hospital Trust, and the Yorkshire Regional Health Authority. We thank Miss R Barclay and Dr J Taylor for valuable technical assistance.

This work was presented in part at the IV European Workshop of Gastroduodenal Pathology and Helicobacter pylori (It $\mathcal{F}$ Gastroenterol 1991; 23 (Suppl 2): 5. [Abstract].

1 Dixon MF. Helicobacter pylori and peptic ulceration: histopathological aspects. $\mathcal{f}$ Gastroenterol Hepatol 1991; 6: $125-30$

2 Wyatt JI, Dixon MF. Chronic gastritis - pathogenetic approach. F Pathol 1988; 154: 113-24.

Rauws EAJ, Langenberg W, Houthoff $\mathrm{HJ}$, Zanen HC, Tytgat GNJ. Campylobacter pyloridis-associated chronic active antral gastritis. Gastroenterology 1988; 94: 33-40.

4 von Wulffen H, Grote HJ, Gatermann S, Loning T, Berger B, Buhl C. Immunoblot analysis of immune response to Campylobacter pylori and its clinical associates. f Clin Pathol 1988; 41: 653-9.

5 Jones DM, Eldridge J, Fox AJ, Sethi P, Whorwell PJ. Antibody to the gastric campylobacter-like organism Antibody to the gastric campylobacter-like organism bution in the normal population. $\mathcal{I}$ Med Microbiol 1986; 22: $57-62$. 
6 Goodwin CS, Blincow E, Peterson G, Sanderson C, Cheng W, Marshall B, et al. Enzyme-linked immunosorbent assay for Campylobacter pyloridis: correlation with presence of C. pyloridis in the gastric mucosa. F Infect Dis 1987; 155: 488-94.

7 Crabtree JE, Mahony MJ, Taylor JD, Heatley RV, Littlewood JM, Tompkins DS. Immune responses to Helicobacter pylori in children with recurrent abdominal pain. $\mathcal{J}$ Clin Pylori in children with 1991 ; 44: 768-71.

8 Crabtree JE, Shallcross TM, Wyatt JI, Taylor JD, Heatley RV, Rathbone BJ, et al. Mucosal humoral immune response to Helicobacter pylori in patients with duodenitis. Dig Dis to Helicobacter pylori

9 Crabtree JE, Taylor JD, Wyatt JI, Heatley RV, Shallcross TM, Tompkins DS, et al. Mucosal IgA recognition of Helicobacter pylori $120 \mathrm{kDa}$ protein, peptic ulceration and gastric pathology. Lancet 1991; 338: 332-5.

10 Karnes WE, Samloff IM, Siurala M, Kekki M, Sipponen P, Kim SWR, et al. Positive serum antibody and negative tissue staining for Helicobacter pylori in subjects with atrophic body gastritis. Gastroenterology 1991; 101: 167-74.

11 Wyatt JI, Shallcross TM, Crabtree JE, Heatley RV. Helicobacter pylori, gastritis and peptic ulceration in the elderly. f Clin Pathol 1992; 45: 1070-4.

12 Siurala M, Sipponen P, Kekki M. Campylobacter pylori in a sample of Finnish population: relations to morphology and
functions of the gastric mucosa. Gut $1988 ; 29: 909-15$.

13 Correa P. A human model of gastric carcinogenesis. Cancer Res 1988; 48: 3554-60.

14 Parsonnet J, Friedman GD, Vandersteen DP, Chang Y, Vogelman $\mathrm{JH}$, Orentreich $\mathrm{N}$, et al. Helicobacter pylori infection and the risk of gastric carcinoma. $N$ Engl f Med 1991; 325: 1127-31.

15 Forman D, Newell DG, Fullerton F, Yarnell JWG, Stacey AR, Wald N, et al. Association between infection with Helicobacter pylori and risk of gastric cancer: evidence from a prospective investigation. BMF 1991; 302: 1302-5.

16 Nomura A, Stemmermann GN, Chyou PH, Kato I, PerezPerez GI, Blaser MJ. Helicobacter pylori infection and gastric carcinoma among Japanese Americans in Hawaii. gastric carcinoma among Japane.

17 Forman D, Sitas F, Newell DG, Stacey A, Boreham J, Peto R, et al. Geographic association of Helicobacter pylori antibody and gastric cancer mortality in rural China. Int $\mathcal{f}$ Cancer 1990; 46: 608-11

18 Correa P, Fox J, Fontham E, Ruiz B, Lin Y, Zavala D, et al. Helicobacter pylori and gastric carcinoma. Serum antibody prevalence in populations with contrasting cancer risks. Cancer 1990; 66: 2569-74.

19 Loffeld RJLF, Willems I, Flendrig JA, Arends JW. Helicobacter pylori and gastric carcinoma. Histopathology 1990; 17: 537-41.

20 Parsonnet J, Vandersteen D, Goates J, Sibley RK, Pritikin J, Chang Y. Helicobacter pylori infection in intestinal- and diffuse-type gastric adenocarcinomas. F Natl Cancer Inst diffuse-type gastric

21 Sipponen P, Kosunen TU, Valle J, Riihela M, Seppala K. Helicobacter pylori infection and chronic gastritis in gastric Helicobacter pylori infection and chron

22 Wee A, Kang JY, Teh M. Helicobacter pylori and gastric cancer: correlation with gastritis, intestinal metaplasia, and tumour histology. Gut 1992; 33: 1029-32.

23 Correa P, Ruiz B. Campylobacter pylori and gastric cancer. In Rathbone BJ, Heatley RV, eds. Campylobacter pylori and gastroduodenal disease. Oxford: Blackwell Scientific, 1989 gastroduode.

24 Talley NJ, Zinsmeister AR, Weaver A, DiMango EP, Carpenter HA, Perez-Perez GI, et al. Gastric adenocarcinoma and Helicobacter pylori infection. $\mathcal{F}$ Natl Cancer Inst
1991; 83: 1734-9.

25 Sobala GM, Crabtree JE, Pentith J, Rathbone BJ, Shallcross TM, Wyatt JI, et al. Screening dyspepsia by serology to Helicobacter pylori. Lancet 1991; 338: 94-6.
26 Figura N, Guglielmetti P, Rossolini A, Barberi A, Cusi G, Musmanno RA, et al. Cytotoxin production by Campylobacter pylori strains isolated from patients with peptic ulcers and from patients with chronic gastritis only. f Clin Microbiol 1989; 27: 225-6.

27 Crabtree JE, Figura N, Taylor JD, Bugnoli M, Armellini A Tompkins DS. Expression of 120 kilodalton protein and cytotoxicity in Helicobacter pylori. $\mathcal{F}$ Clin Pathol 1992; 45: cytotoxicit

28 Fox JG, Correa P, Taylor NS, Thompson N, Fontham E, Janney $\mathrm{F}$, et al. High prevalence and persistence of cytotoxin positive Helicobacter pylori strains in a population with high prevalence of atrophic gastritis. Am f Gastroenterol 1992; 87 prevalence.

29 Lauren P. The two histological main types of gastric carcinoma: diffuse and so-called intestinal-type carcinoma. Acta Pathol Microbiol Scand 1965; 64: 31-49.

30 Crabtree JE, Heatley RV, Losowsky MS. Glycoprotein synthesis and secretion by cultured small intestinal mucosa in coeliac disease. Gut 1989; 30: 1339-43.

31 Morgan AG, Crabtree JE, Heatley RV, Goodwin PGR. The role of $\mathrm{H}$ pylori serology in initial assessment of patients with dyspepsia. Gut 1991; 32: A570.

32 Crabtree JE, O'Mahony S, Wyatt JI, Heatley RV, Vestey JP, Howdle PD, et al. Helicobacter pylori serology in patients with coeliac disease and dermatitis herpetiforms. w Clin Pathol 1992; 45: 597-600.

33 Leunk RD, Johnson PT, David BC, Kraft WG, Morgan DR. Cytotoxic activity in broth-culture filtrates of Campylobacter pylori. Med Microbiol 1988; 26: 93-9.

34 Cover TL, Dooley CP, Blaser MJ. Characterisation of and human serological response to proteins in Helicobacter pylori broth culture supernatants with vacuolizing cytotoxi activity. Infect Immun 1990; 58: 603-10.

35 Glupczynski Y, Burette A, Goosens H, DePrez C, Butzler JP. Effect of antimicrobial therapy on the specific serological response to Helicobacter pylori infection. Eur $\mathcal{7}$ Clin Microbiol Infect Dis 1992; 11: 583-8.

36 Hirschl AM, Rathbone BJ, Wyatt JI, Berger J, Rotter ML. Comparison of ELISA antigen preparations alone or in Comparison of ELISA antigen preparations alone or in tion. F Clin Pathol 1990; 43: 511-3.

37 Ho SA, Hoyle JA, Lewis FA, Secker AD, Cross D, Mapstone NP, et al. Direct polymerase chain reaction test for detection of Helicobacter pylori in humans and animals. f Clin Microbiol 1991; 29: 2543-9.

38 Clayton CL, Kleanthous H, Coates PJ, Morgan DD, Tabaqchali S. Sensitive detection of Helicobacter pylori by using polymerase chain reaction. $\mathcal{F}$ Clin Microbiol 1992; 30: 192-200.

39 Le J, Vilcek J. Interleukin 6: a multifunctional cytokine regulating immune reactions and the acute phase protein response. Lab Invest 1989; 61: 588-602.

40 Crabtree JE, Shallcross TM, Heatley RV, Wyatt JI. Mucosal tumour necrosis factor alpha and interleukin- 6 in patients with Helicobacter pylori associated gastritis. Gut 1991; 32: 1473-7.

41 Hedges S, Svensson M, Svanborg C. Interleukin-6 response of epithelial cell lines to bacterial stimulation in vitro. Infect Immun 1992; 60: 1295-301.

42 Nakamura H, Yoshimura K, Jaffe HA, Crystal RG. Interleukin-8 gene expression in human bronchial epithelial cells. f Biol Chem 1991; 266: 19611-7.

43. Negrini R, Lisato L, Cavazzini L, Maini P, Gullini S, Basso O, et al. Monoclonal antibodies for specific immunoperoxidase detection of Campylobacter pylori. Gastroenterology 1989; 96: 414-20.

44 Negrini R, Lisato L, Zanella I, Cavazzini L, Gullini S, Villanacci $\mathrm{V}$, et al. Helicobacter pylori infection induces antibodies cross-reacting with human gastric mucosa. Gastroenterology 1991; 101: 437-45. 